\title{
Mechanical Properties of Soft Magnetic Composites at the Temperature of Liquid Nitrogen
}

\author{
M. Przybylski*, D. Kapelski and B. Ślusarek \\ Tele \& Radio Research Institute, Ratuszowa 11, 03-450 Warsaw, Poland
}

\begin{abstract}
Soft magnetic composites are used in a wide range of applications working in different environmental conditions, between others, in different temperatures. Nowadays, devices often work in cryogenic temperatures. The paper shows influence of liquid nitrogen temperature on mechanical properties of soft magnetic composites prepared from ABC100.30 powder bonded by epoxy resin. Mechanical properties of samples were measured in room and liquid nitrogen temperatures. Compressive strength and transverse rapture strength increase with decreasing temperature. This type of soft magnetic composite can be applied in magnetic circuits of devices working in cryogenic temperatures. The results of measurement show that new devices, especially electric machines, working in these temperatures can be designed with higher mechanical loadings than devices working at room temperature.
\end{abstract}

DOI: 10.12693/APhysPolA.131.1199

PACS/topics: 75.50.Cc, 81.05.Zx, 81.20.Ev, 81.70.Bt

\section{Introduction}

Soft magnetic materials are one of the main materials for preparation of magnetic circuits of electromagnetic devices. Nowadays, electrical steel is mainly used as soft magnetic material for preparation of magnetic circuit of electric motors. This type of materials characterized good magnetic properties, but their disadvantages are a complicated technological process and a relatively high price of manufacture.

Powder metallurgy is characterized by low production cost, low waste of materials and easy recycling. There are two basic methods making soft magnetic parts by powder metallurgy: sintering and bonding magnetic particles by resin [1-3].

Sintered soft magnetic parts have low resistivity, therefore they are applied only in devices with a constant or low frequency magnetic field. Soft magnetic composites (SMC), also called dielectromagnetics consist of ferromagnetic particles distributed in a matrix of a electrically insulated binding agent. Metal powder is produced in several ways, but the most commonly used is the atomization technique. In this technique a stream of molten metal is atomized by gas or water under high pressure which leads to creation of fine liquid metal droplets which then solidify resulting in powder particles.

Elements from magnetic composites are prepared by a compression moulding technique which involves compaction of powder in a die under high pressure. In a next step, "green compacts" are cured in a furnace at melting temperature of binding agent. In the case of compression moulding techniques, an air atmosphere is used during the curing due to the presence of the binding agent which protects against oxidation of this type of element.

*corresponding author; e-mail: marek.przybylski@itr.org.pl
The basic material for preparing soft magnetic composites are Fe powders. The main feature of these materials is that iron particles are insulated by a thin organic or inorganic coating. Insulation particles can be made while making particles or by preparing a mixture of iron powder and resin powder before compression. Magnetic composites prepared by bonding particles by resin compared with sintered elements achieved a lower magnetic flux density, however, owing to their relative high resistivity, they can be applied in power devices with $50 \mathrm{~Hz}$ and higher frequency approximately up to $100 \mathrm{kHz}$ [4].

Soft magnetic composites (SMCs) are being evaluated to replace conventional electrical steel sheets in numerous devices and systems $[5,6]$. SMCs also enable building of new structures of electric motors and devices $[7,8]$. It is directly related to physical properties of soft magnetic composite, among others, three-dimensional magnetic properties, the possibility to tailor their physical properties, and very low eddy current loss. One of the most important features is an ease of manufacturing magnetic circuits. Magnetic parts are produced in readymade form in the case of dimensions and size and do not require additional machining. The temperature of curing is smaller than sintering temperature and the process does not need protective atmosphere. It is the reason that this kind of technology is cheaper than sintering technology.

Electromagnetic devices with magnetic circuits are applied in a wide range from home appliances to aerospace devices. This means that these devices work in different environmental conditions, between other different temperatures.

Liquefied gases, such as liquid nitrogen and liquid helium, are used in many cryogenic applications, like for example, cooling of superconducting magnets or supercomputers. Electric drive pumps operating in liquid gas atmospheres may be applied in devices for transport and storage of liquid nitrogen, hydrogen or oxygen [9-13]. 
All materials, including magnetic materials, change physical properties with changing temperature. Changes of physical properties of magnetic circuit of electric motors influence the operational parameters of machines. The most important parameter of magnetic circuits is their magnetic properties, but in many applications mechanical and electrical properties are very important, too. Knowledge about these parameters is very important for designers of electromagnetic devices.

Earlier investigation shows that magnetic properties of soft magnetic composites from $\mathrm{Fe}$ powders in the range of temperature from $-40{ }^{\circ} \mathrm{C}$ to $+100^{\circ} \mathrm{C}$, are almost unchanging [14]. Decrease of temperature to the temperature of liquid nitrogen changes behavior of composites. The research of the influence of nitrogen temperature on magnetic properties of soft magnetic composites showed that their magnetic properties change with decrease of temperature. Lowering the temperature leads to an increase in power losses and a decrease in relative permeability and resistivity $[15,16]$.

The investigation of mechanical properties of soft magnetic composites prepared from $\mathrm{Fe}$ powder, in the range of temperature from $-40^{\circ} \mathrm{C}$ to $+100^{\circ} \mathrm{C}$, showed that increase in temperature above room temperature causes a decrease in mechanical properties, while decrease in temperature below room to $-40^{\circ} \mathrm{C}$ temperature causes an increase in mechanical properties of SMC. Investigation was conducted on samples prepared from Somaloy 500 (Höganäs AB Company) [17].

Influence of cryogenic temperature was conducted on samples prepared from Somaloy 700 and AncorLam. The result of investigation of transversal rupture strength and compressive strength shows that mechanical properties enhance with decreasing temperature [18]. Both of these powders are insulated by dielectric during the production process [17].

In scientific papers there is not a lot of information about the behaviour of elements from soft magnetic composites prepared from iron powders bonded by epoxy resin.

Growing application of electromagnetic devices in liquid gases require knowledge about physical properties of soft magnetic composites in cryogenic temperatures. Designers of electric motors have to take it into account while designing the motors.

The main goal of investigation is to broaden knowledge about behaviour of soft magnetic composites in cryogenic temperatures. Elements from a soft magnetic composite prepared from ABC100.30 powder were investigated. The mechanical properties of samples from this powder were measured and analyzed.

\section{Materials and experimental details}

Specimens investigated in the study were produced from commercially available pure iron powder produced by water atomization techniques type ABC100.30 (Höganäs $\mathrm{AB}$ Company). It is powder with outstanding compressibility and chemical purity. The grain size is between 45 and $150 \mu \mathrm{m}$ (70\%). This type of powder can be used in applications where very good soft magnetic properties are required. Preparation of composite elements made of this powder require adding a bonding agent. For this purpose epoxy resin Epidian 100 (Organika Sarzyna) was selected. In Fig. 1 particles of powder are shown.

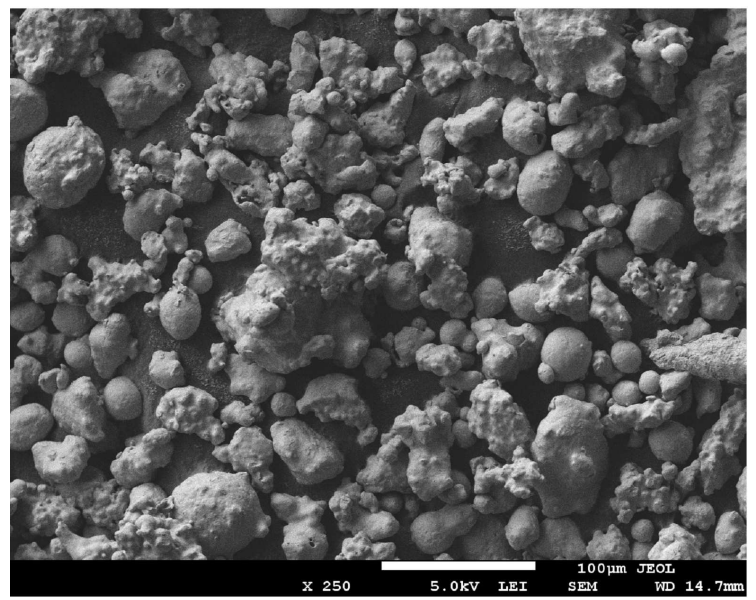

Fig. 1. SEM photo of particles of powder ABC100.30.

A mixture of iron powder, resin in a form of powder and lubricant was prepared. The samples with contents $0.25,0.50$, and $0.75 \mathrm{wt} \%$ of resin were made. Then mixture was pressed in a die. Due to earlier experience, the pressure for all samples was $800 \mathrm{MPa}[13,14]$. "Green compacts" were hardened in a furnace in temperature $190{ }^{\circ} \mathrm{C}$ in air atmosphere. The hardening time for these samples was fixed at $120 \mathrm{~min}$.

The main goal of investigation was to find the correlation between mechanical properties of soft magnetic composites and changes of temperature from room temperature to liquid nitrogen temperature $-195.8^{\circ} \mathrm{C}$. Examination of compressive strength and transverse rupture strength was performed using the universal testing machine Instron 1115. The measurements of compressive strength were conducted based on Polish standard $\mathrm{PN}-\mathrm{H}-04947$ and transverse rupture strength were made according to ISO 3325 standard.

The specimens for compressive strength were cylindrical in shape, $10 \mathrm{~mm}$ in diameter, $14 \mathrm{~mm}$ in height. The specimens for transverse rupture strength were beam shape with a dimension of $12 \mathrm{~mm}$, in a width of $30 \mathrm{~mm}$ in length and an average height of $6 \mathrm{~mm}$.

The density of prepared samples was calculated based on their mass and volume.

The compressive strength and the transverse rupture strength of samples prepared from powder with a different content of resin were determined at room temperature. In the second series of measurements, samples were immersed in liquid nitrogen before the test at a time of $10 \mathrm{~min}$ for cooling. During the measurement, samples were constantly immersed in liquid nitrogen. The con- 
tainer for samples is shown in Fig. 2.

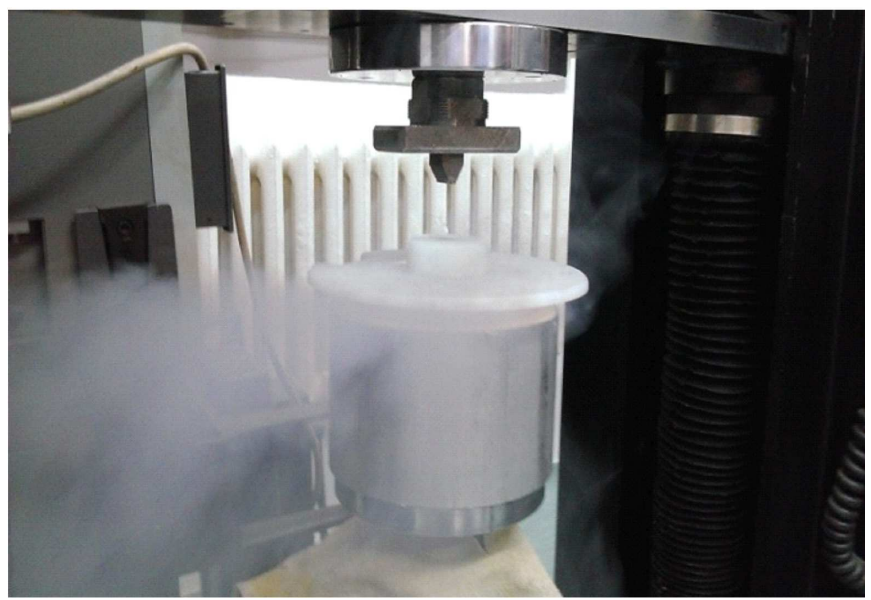

Fig. 2. Container with liquid nitrogen installed in a machine Instron 1115 during stabilization of temperature.

\section{Results and discussion}

Measurements of density, compressive strength and transverse rupture strengths of soft magnetic composites were conducted.

\subsection{Determination of density of soft magnetic composites}

Density of samples prepared from ABC100.30 containing different epoxy resin was measured. The results are shown in Table I. For comparison purpose the results of measurement of samples from Somaloy 700 and AncorLam were shown [13].

\section{TABLE I}

Density of soft magnetic composites.

\begin{tabular}{c|c|c}
\hline \hline Powder & $\begin{array}{c}\text { Epoxy resin content } \\
{[\mathrm{wt} \%]}\end{array}$ & $\begin{array}{c}\text { Density } \\
{\left[\mathrm{g} / \mathrm{cm}^{3}\right]}\end{array}$ \\
\hline ABC100.30 & 0.25 & 7.26 \\
ABC100.30 & 0.50 & 7.20 \\
ABC100.30 & 0.75 & 7.10 \\
Somaloy 700 & - & 7.39 \\
AncorLam & - & 7.31
\end{tabular}

The results of measurements of density show that the density of soft magnetic elements depends on the type and content of the binding agent. The basic material in all samples is iron powder, but the type of binding material and method of covering particles by the binding agent are different. The density of elements from Somaloy 700 and AncorLam are bigger than the density of elements from ABC100.30 powder. Particles of Somaloy 700 and AncorLam are covered by a binding and lubrication agent during the production process of powder. The layer of dielectric evenly covers the surface of iron particles. In the case of powders with epoxy resin, the density of samples are smaller and decrease with the increase of amount of resin. Those samples were prepared from pure iron powder mixed with powdered epoxy resin.

\subsection{Determination of compressive strength of soft magnetic composites}

Mechanical property - compressive strength was measured. The results of testing compressive strength of samples from iron powder and epoxy resin powders in room temperature and liquid nitrogen temperature are presented in Table II. For comparison, the purpose value of compressive strength for Somaloy 700 and AncorLam are shown [14]. All samples were measured on the same dimension of samples and used the same testing equipment.

TABLE II

Influence of temperature on compressive strength of soft magnetic composites.

\begin{tabular}{c|c|c|c}
\hline \hline & Epoxy resin & \multicolumn{2}{|c}{ Compressive strength } \\
\cline { 3 - 4 } Powder & content [wt\%] & at $20^{\circ} \mathrm{C}$ & at $-195.8^{\circ} \mathrm{C}$ \\
\hline ABC100.30 & 0.25 & 205 & 578 \\
ABC100.30 & 0.50 & 223 & 601 \\
Somaloy 700 & - & 513 & 804 \\
AncorLam & - & 304 & 779
\end{tabular}

Figure 3 shows e.g. curves of compressive stress in a function of strain for $\mathrm{ABC} 100.30$ with $0.5 \mathrm{wt} \%$ of epoxy resin.

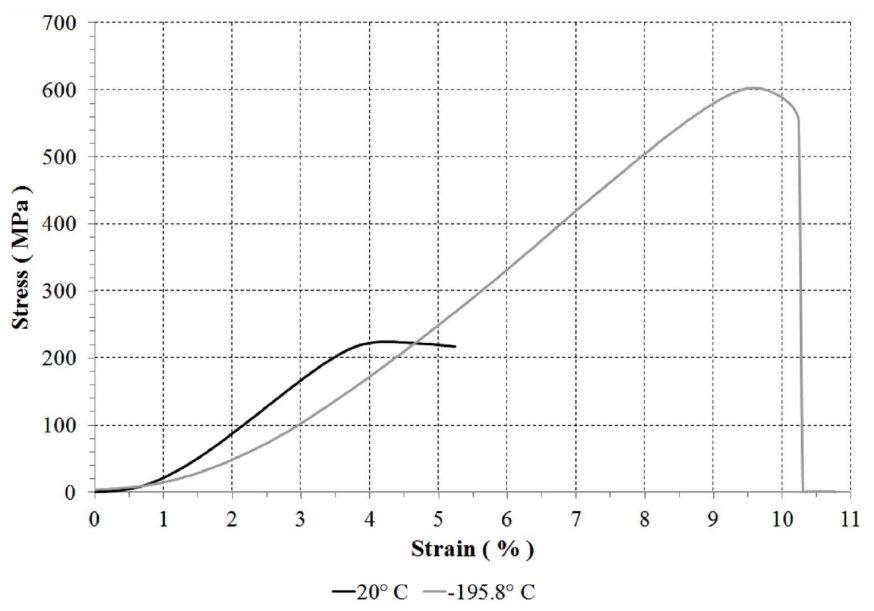

Fig. 3. Influence of temperature on compressive stress for composites from $\mathrm{ABC} 100.30$ with $0.5 \mathrm{wt} \%$ of epoxy resin.

Mechanical properties of soft magnetic composites depend on the type of powder and mainly on the type of binding agent and method of preparing the mixture of powder and binding agent. As Table II shows, the best compressive strength is demonstrated by composites from Somaloy 700, the worse composites from ABC 100.30 powder bonded by $0.25 \mathrm{wt} \%$ of epoxy resin. Compressive strength of soft magnetic composites prepared from 
different powders and binding agents increase considerably along with the decrease of temperature from room temperature to liquid nitrogen temperature. Increase of compressive strength of soft magnetic composites prepared from Somaloy 700 is about $56 \%$. In the case of samples from AncorLam, powder the increase is bigger and is $156 \%$. The increase of compressive strength of samples from ABC.100.30 powder depend on the contents of epoxy resin. For the samples with $0.25 \mathrm{wt} \%$ of epoxy resin, is about $182 \%$, for samples with $0.50 \%$ of resin, $169 \%$. The increase of epoxy resin increases compressive strength in both temperatures. Comparing the compressive strength, all samples indicate that the percentage increase of compressive strength for samples from pure iron bonded by epoxy resin is the largest.

\subsection{Determination of transverse rupture strength of soft magnetic composites}

Transverse rapture strength of prepared samples from ABC.100.30 was measured in room and nitrogen temperature. Results are presented in Table III. The table contains values of transverse rapture strength composites from Somaloy 700 and AncorLam powders for comparison purpose [14].

TABLE III

Influence of temperature on transverse rupture strength (TRS) of soft magnetic composites.

\begin{tabular}{c|c|c|c}
\hline \hline & Epoxy resin & \multicolumn{2}{|c}{ TRS } \\
\cline { 3 - 4 } Powder & content [wt\%] & at $20^{\circ} \mathrm{C}$ & at $-195.8^{\circ} \mathrm{C}$ \\
\hline ABC100.30 & 0.25 & 62.8 & 118.4 \\
$\mathrm{ABC} 100.30$ & 0.50 & 77.7 & 150.4 \\
$\mathrm{ABC} 100.30$ & 0.75 & 99.4 & 159.6 \\
Somaloy 700 & - & 37.5 & 54.9 \\
AncorLam & - & 32.9 & 55.3
\end{tabular}

Figure 4 shows e.g. curves of flexural stress in a function of strain for $\mathrm{ABC} 100.30$ with $0.5 \mathrm{wt} \%$ of epoxy resin.



Fig. 4. Influence of temperature on flexural stress for a composite from $\mathrm{ABC} 100.30$ with $0.5 \mathrm{wt} \%$ of epoxy resin.
As results in Table III show, the highest transverse rupture strength of soft magnetic composites have samples made of ABC.100.30 powder with 0.75 wt\% of epoxy resin, the lowest samples from AncorLam powder. With decrease of temperature for all types of soft magnetic composites transverse rupture strength increases. In the case of composite from Somaloy 700 the increase is about $46 \%$, for AncorLam about $68 \%$, for $\mathrm{ABC} 100.30$ with $0.25 \mathrm{wt} \%$ of epoxy resin about $89 \%$, for $0.50 \mathrm{wt} \%$ about $94 \%$ and for $0.75 \mathrm{wt} \%$ about $60 \%$. For comparison, the transverse rupture strength of pure epoxy resin was measured. With a decrease in temperature, the value of their transverse rupture strength increases by about $52 \%$ from 85.5 $\mathrm{MPa}$ to $129.6 \mathrm{MPa}$. All samples from pure iron bonded by epoxy resin demonstrated a higher value of transverse rapture strength in both temperature than composites prepared from powder with a layer of binding agent made during technology process of preparing powders.

\section{Conclusion}

The results of the investigation show that mechanical properties of soft magnetic composites increase with decrease of temperature from room to liquid nitrogen temperature. This means that this type of material, from this point of view, can be used in many devices working in nitrogen temperatures. The changes of mechanical properties of soft magnetic composites depend on the type of binding agent and method of preparing powder with binding material, by covering iron powder by a binder during production of powder or by preparing a mixture of iron powder with a binding agent before compression.

The increase of mechanical properties in the temperature below room temperature is most likely caused by the change of epoxy resin structure and increase of the glassy state phases. Below glass transition temperature, an epoxy resin is hard but brittle and it increases bending and compressive strength of composites [19-21].

The result of investigation widen the knowledge about behavior of soft magnetic composites in cryogenic temperatures. Changes of physical properties with changing temperature have to be considered while designing new cryogenic equipment with magnetic circuits from soft magnetic composites.

\section{References}

[1] B. Ślusarek, Prz. Elektrotechniczny 86, 16 (2010).

[2] J.A. Bas, J.A. Calero, M.J. Dougan, J. Magn. Magn. Mater. 254-255, 391 (2003).

[3] M.R. Marucci, K.S. Narasimhan, in: Proc. Euro PM2011 Congress \&5 Exhibition, Barcelona (Spain), 2011, p. 285.

[4] H. Shokrollahi, K. Janghorban, J. Mater. Process. Technol. 189, 1 (2007).

[5] L. Frayman, S. Quinn, R. Quinn, D. Green, F. Hanejko, Powder Metall. 58, 335 (2015).

[6] S.H. Lee, Y.J. Kim, K.S. Lee, S.J. Kim, J. Magn. 20, 444 (2015). 
[7] A. Schoppa, P. Delarbre, IEEE Trans. Magn. 50, 2004304 (2014).

[8] T. Ishikawa, Y. Sato, N. Kurita, IEEE Trans. Magn. 50, 8105304 (2014).

[9] L. Długiewicz, J. Kołowrotkiewicz, B. Ślusarek, W. Szeląg, in: Proc. 21th Symp. on Power Electronics, Electrical Drives, Automation and MotionSPEEDAM, Sorrento (Italy), Eds.: E. Pagano, E. Yamada, IEEE, 2012, p. 822.

[10] D. Kapelski, B. Jankowski, M. Przybylski, B. Ślusarek, Techn. Trans. Electr. Eng. 112 281 (2015).

[11] J. Kołowrotkiewicz, M. Barański, W. Szeląg, L. Długiewicz, Compel Int. J. Comp. Math. Electr. Electron. Eng. $\mathbf{2 6}$ 952 (2007).

[12] Y. Abe, A.A. Nakagawa, M. Watada, S. Torri, K. Yamane, D. Ebihara, IEEE Trans. Magn. 32, 5025 (1996).

[13] I.R. Walker, Rev. Sci. Instrum. 64, 814 (1993).

[14] B. Ślusarek, M. Przybylski, in: Proc. 13th Symp. on Fundamental Problems of Power Electronics Electromechanics and Mechatronics - PPEEm, Wisła (Poland), Ed. K. Kluszczyński, Polish Scientific Society for Theoretical and Applied Electrical Engineering, 2009, p. 226.
[15] B. Jankowski, D. Kapelski, M. Karbowiak, M. Przybylski, B. Ślusarek, Powder Metall. 57, 155 (2014).

[16] B. Ślusarek, J. Gromek, M. Przybylski, B. Jankowski, D. Kapelski, M. Karbowiak, in: Proc. 15th Int. Symp. on Electromagnetic Fields in Mechatronics, Electrical and Electronic Engineering - ISEF, Funchal (Portugal), Eds.: C.L. Antunes, S. Wiak, Portuguese Association for the Development of Electrical Engineering (APDEE), Coimbra 2011.

[17] B. Ślusarek, P. Gawryś, M. Przybylski, Stud. Appl. Electromagn. Mech. 30, 34 (2008).

[18] D. Kapelski, B. Jankowski, M. Przybylski, B. Ślusarek, Arch. Metall. Mater. 60, 1323 (2015).

[19] M. Urbaniak, Polimery 56, 240 (2011).

[20] J. Rieger, Polym. Test 20, 199 (2001).

[21] A. Hale, C.W. Macosko, H.E. Bair, Macromolecules 24, 2610 (1991). 